\title{
Overview and Suggestions for Common Production Base Planning in the Outdoor Ornamental Plants Sector
}

\author{
Okan Yeler (Corresponding author) \\ Muradiye Vocational School, Van Yuzuncu Yil University, Van, turkey \\ E-mail: okanyeler@yyu.edu.tr \\ Neslihan Yonca Satir \\ Van Directorate of Provincial Agriculture and Forestry \\ PHD Student, Department of Soil Science and Plant Nutrition, \\ The Faculty of Agriculture, Cukurova University, Adana, Turkey \\ E-mail: n.yonca1@gmail.com
}

\begin{abstract}
The main purpose of establishing a cooperation with sectoral participating stakeholders and as a result of producing production base planning; Within the framework of public administrations, development plans, programs, relevant legislation and the basic principles they adopt, it is to create future missions and visions, to determine strategic goals and measurable targets, to measure performances in line with pre-determined indicators, and to contribute to the development of our country by target and evaluation of this process. The basic principle to be put forward within the scope of this study is to bring the outdoor ornamental plants sector, which has a large commercial share in exports and imports in our country in the agricultural field, to the desired level and to be in the upper ranks in the world ranking. restructuring of the corporate identity for the sector in this framework and the identification of common strategic objectives and recommendations on the subject of the solution has been developed.
\end{abstract}

Keywords: Outdoor Ornamental Plants, Common Production Base, Ornamental Plants, Production Base Planning

DOI: $10.7176 /$ JSTR/6-10-07

\section{Dış Mekân Süs Bitkileri Sektöründe Ortak Üretim Üssü Planlamasına Bakış ve Öneriler}

Özet

Sektörel katılımcı paydaşlar ile birliktelik oluşturmak ve bunun sonucunda ortak bir üretim üssü planlaması ortaya koyabilmenin temel amacı; kamu idareleri, kalkınma planları, programlar, ilgili mevzuat ve benimsedikleri temel ilkeler çerçevesinde geleceğe ilişkin misyon ve vizyonlarını oluşturabilmektir. Bununla beraber stratejik amaçlar ve ölçülebilir hedefler saptamak, performansları önceden belirlenmiş göstergeler doğrultusunda ölçümler yaparak bu sürecin izlenmesi ve değerlendirilmesi hedefi ile potansiyel değerliliğinde ülkemizin gelişimine katkı sağlamaktır. Bu çalışma kapsamında ortaya konulmak istenen temel ilke tarımsal alanda ülkemizde ihracat ve ithalatta büyük bir ticari payı bulunan dış mekân süs bitkileri sektörünün istenilen seviyeye getirilebilmesi ve dünya sıralamasında üst bölümlerde yer alabilmesi çalışmalarına katkı sağlayabilmektir. Bu çerçevede sektöre yönelik kurumsal kimliğin yeniden yapılanması ve ortak stratejik hedeflerin belirlenmesi konu başlıklarında çözüm ve öneriler geliştirilmiştir.

Anahtar Kelimeler: Dış Mekan Süs Bitkileri, Ortak Üretim Üssü, Süs Bitkileri, Üretim Üssü Planlamasi

79 | P a g e

www.iiste.org 


\section{Giriş}

\section{1. Tarihi Gelişim}

Arazi mülkiyet rejiminin ülkemizde bugüne kadar geçirdiği evreleri görme açısından Cumhuriyetten önceki geçmiş uygulama ve arazi mülkiyeti oluşumlarına bakmakta yarar vardır. Bunların analizleri de yapılmıştır. İște günümüze geldiğimizde, Tarım Reformu Genel Müdürlüğ̈̈, 3083 sayılı Sulama Alanlarında Arazi Düzenlemesine Dair Tarım Reformu Kanunu uyarınca Bakanlar Kurulu kararı ile uygulama alanı ilan edilen yerlerde, 3083 sayılı kanunun Amaç başlı̆̆ altındaki 1. maddede belirtilen hükümler çerçevesinde faaliyetlerini sürdürmektedir. Bu hükümleri iki temel bölümde değerlendirmek mümkündür. Birinci bölümde kamulaştırma, arazi dağılımı, arazi toplulaştırması, arazi kiralaması gibi mülkiyetle ilgili düzenlemeler, ikinci bölümde ise toprağın verimli şekilde işletilmesi, işletilmesinin korunması, tarımsal üretimin arttırılması, tarımda istihdam imkânlarının geliştirilmesi, yerleşim yerlerinin düzenlenmesi gibi iktisadi verimlilik ilkeleri yer almaktadır [3].

Türkiye genelinde 2009 yılı sonu itibariyle 42 il, 150 ilçe ve 2590 yerleşim biriminde 692.000 hektar alanda arazi toplulaştırma çalışması tamamlanmıştır. İşte kalkınmada tanım, tarım sektörünün en önemli özelliği dünyadaki tüm ülkeler için stratejik öneme sahip olan bir sektör olmasıdır. Güncel veriler bize bugün tanımın büyük bir girişimcilik sektörü olduğunu ve ileri teknoloji ve bilginin uygulama alanı haline geldiğini, dolayısı ile burada büyük bir katma değer zincirinin kurulabileceğini göstermektedir. Esasen son yıllarda dünyada tecrübe edilen küresel iklim dengesizlikleri, sektörün stratejik niteliği ve nihayet Türkiye'nin tarımsal potansiyeli bir arada düşünüldüğünde tarımın Türkiye'nin kalkınmasında merkezi bir rol oynaması gerektiği kendiliğinden ortaya çıkacaktır. İktisadi tarihi verileri, tarımsal potansiyeli neredeyse hiç olmayan Japonya da içinde olmak üzere belli bir alan ve nüfus büyüklüğüne sahip olup da tanımsız sanayileşen ilke örneğinin olmadığını göstermektedir. Siyasi bağımsızlığının ve doğal bitki örtüsünün korunup geliştirilebilmesi anlamında tarım sektörünün önemi artarak devam edecektir [2].

$\mathrm{Bu}$ sektörde süs bitkileri, bu bitkiler dünyanın birçok ülkesinde ve Türkiye'de ekonomiye önemli katkılar sağlayan, kullandığı iş gücü miktarı bakımından da sosyal yaşamdaki etkisi çok fazla olan önemli bir tarımsal üretim dalını oluşturmaktadır [6].

\section{2. Ülkemizde Süs Bitkilerinin Tarımsal Varlığı ve Yapısı}

Türkiye, süs bitkileri yetiştiriciliğinde uygun iklimsel ve coğrafi koşulları, pazar ülkelere yakınlığı ve ucuz işgücüne sahip olması gibi nedenlerle önemli avantajlara sahiptir. Türkiye'de ticari anlamda kesme çiçek üretimi, 1940'lı yıllarda İstanbul ve çevresinde başlamış, daha sonra Yalova da önemli bir üretim merkezi konumuna gelmiştir. 1985 yılından itibaren Antalya'dan yapılmaya başlayan kesme çiçek ihracatı, çiçek üretim alanlarını bu bölgede hızla artırmıştır. İhracata yönelik üretimin dolaylı yollarla teşvik edilmesi ve bitki materyali ithaline getirilen kolaylıklar, kesme çiçek üretim alanı ve miktarında önemli artışların ortaya çıkmasını sağlamıştır [7].

Türkiye'de 28 ilde süs bitkileri üretimi yapılmaktadır. Üretimin en fazla yapılldı̆̆ iller sırasıla İzmir, Sakarya, Antalya, Yalova, Bursa ve Isparta'dır. Antalya ve İzmir kesme çiçek üretiminde en önemli illerdir. Marmara ve Ege Bölgesinde (İstanbul, Yalova, İzmir, Aydın) yapılan kesme çiçek üretimi genellikle iç pazara yöneliktir. Antalya bölgesinde ise çoğunluğu seralarda olmak üzere yüksek kaliteli ve ihracata yönelik üretim yapılmaktadır. Sakarya, Yalova, İstanbul, Adana, Osmaniye iç ve dış mekân bitkileri üretiminde önemli yere sahiptir. Sakarya bölgesi de istatistiklerden görülmeyen ama son 5 yıldır çok önemli dış mekân süs bitkileri üretimi yapılan bir bölgedir. Bu bölgede üretimin ihracata yönelik konumlandırıldığı 500 hektara yakın üretim alanı bulunmaktadır. Özellikle Sakarya merkez olmak üzere Arifiye, Sapanca, Pamukova ilçelerinde yoğun üretim alanları görülmektedir. Türkiye süs bitkileri üretimi itibariyle dünya üretiminde yaklaşı binde 7'lik bir paya sahiptir [5].

\section{3. Süs Bitkileri Sektörü Sinıflandırması}

Süs bitkileri sektörü, bitkisel üretim içinde önemli bir yere sahip olan ve ekonomiye büyük katma sağlayan etkili bir sektör olarak kabul edilmektedir. Ülkemiz çok çeşitli ekolojik bölgeye sahip olup, iklim ve toprak özellikleri bakımından süs bitkileri yetiştiriciliğine son derece uygundur ve aynı zamanda bir çok süs bitkisinin gen kaynağıdır. Süs bitkileri, yaygın olarak kullanım amaçlarına göre siniflandırılmaktadır.

\section{Kesme Çiçekler}

Kesme çiçek amaçlı yetiştiricilik ve yetiştirilen türleri içermektedir.

$80 \mid \mathrm{P}$ a g e

www.iiste.org 
İç Mekân (Saksılı) Süs Bitkileri

İç mekânda kullanılmak üzere saksı ve kaplarda yetiştirilerek pazarlanan bitki tür ve çeşitlerini kapsamaktadır.

\section{Dış Mekân Süs (Tasarım) Bitkileri}

Dış mekânda peyzaj uygulamalarında kullanılmak üzere üretilip pazarlanan tür ve çeşitleri içermekte, süs ağaç ve ağaç̧̧ıları, mevsimlik tek ve çok yıllık çiçekler, yer örtücü olarak kullanılan diğer türler ve süs çimleri bu sınıf içinde değerlendirilmektedir.

\section{Çiçek Soğanları}

$\mathrm{Bu}$ sınıf ülkemiz gerçeklerinden doğmuş, ihraç edilmek üzere doğadan toplanan ve/veya kültür koşullarında üretimi yapılan doğal soğanl, yumrulu ve rizomlu bitki türlerini (geofitleri) kapsamaktadır Armonize sisteme göre, kağıg ve kağıt ürünleri Gümrük Tarife İstatistik Pozisyon Kodları (GTiP) aşağıda verilmektedir.

\section{GTìP No Ürün Tanımı}

0601 Çiçek Soğanları, 0602 Canlı Bitkiler, 0603 Kesme Çiçekler , 0604 Yosunlar ve Ağaç Dalları (5).

\section{Stratejik Planın Ulusal Kalkınma Stratejisi Politikası ve Planları İle İlişkisi}

Süs bitkileri kalkınma planlarında, Rekabet Gücünün Arttırılması sürecinde üretim ve tüketiminde önemli değişiklikler yaşanmakta, büyük bir rekabet ortamı oluşmaktadır. Dünya'da yaklaşık 145 ülkede 220.000 hektar alanda süs bitkisi üretimi yapılmaktadır. Ticaret hacmi ise 50 milyar dolar civarındadır. Bilgi birikimi ve hızlı uygulamaya aktarılan teknolojik gelişmeler sonucu süs bitkisi üretimi, öncelikli olarak $\mathrm{ABD}$, Hollanda ve Japonya gibi gelişmiş ülkelerde hızlı bir büyüme göstermiştir. Kuzey Amerika'da ABD en büyük üretici ülke konumundadır.

Kolombiya ve Ekvator'dan gelen yoğun kesme çiçek ithalatı, ABD'nin süs bitkisi üretiminde saksılı bitkilere yönelmesine neden olmuştur [2].

Hollanda ise ileri teknoloji kullanımı, re-export ve Almanya pazarına yakınlık avantajları ile dünya pazarındaki yerini ve önemini korumaya devam etmiştir. Hollanda yüksek ücretle işçi kullanma zorunluluğu ve iklimin fazla uygun olmaması gibi dezavantajları bulunmasına rağmen bunları yüksek verimlilik, etkili dağıtım ağı ve yeni ürün geliștirme çabaları ve çalıșmaları ile kapatmıștır. Ülkede kaliteye, verimliliğe ve teknolojik değişimlere kolaylıkla ulaşlabilme ve değişen şartlara hemen uyum sağlanabilmektedir. Ayrıca Hollanda, Avrupa ülkeleri arasında en geniş kapalı alana sahip konumdadır. Cam seralarda yoğun üretim yapmaktadır. Sektörde en önemli konumdaki Asya ülkesi ise Japonya'dır. Batı Afrika, Latin Amerika, Asya ülkeleri çiçek üretim ve ihracatını önemli ölçüde geliştirerek söz sahibi olmaya başlamışlardır. Bugün Afrika'da en önemli süs bitkisi üreticisi ülkelerden olan Kenya ve Zimbabve dikkat çekici gelişmeler göstermektedirler. Afrika çiçek endüstrisi Avrupa pazarına odaklanmıştır.

Güney Amerika ülkelerinde yeni teknolojileri uygulamaya açık olup, son yıllarda büyük miktarlı yabancı sermaye girişi ile üretim alanlarını arttırmıştır. Bölgede Kolombiya ve Ekvator önemli kesme çiçek üretici konumundadır. Bunların temel sektörü iklimdir. Ucuz toprak ve bol suyun olması da üretim için önemli avantaj sağlamaktadır. Bunlar uygun uluslararası pazarlarda standart ürünler üretme ve pazarlama için olumlu, uygun şart ve koşullara sahiptirler. Asya'da ise Kore, üretimi ve tüketimi artan bir ülke olarak sektörel önemini arttırmaktadır. Bahse konu ülkeler ekolojik ve işgücü üstünlükleri sayesinde özellikle kesme çiçek üretiminde kullanarak ürünlerini gelişmiş ülkelere ihraç etmektedirler. Bu ülkelerin ihracat payının artmasına etki eden diğer bir yapı da ABD Kolombiya'da, Almanya Hollanda'da, diğer Avrupa ülkelerinden, İspanya ise İsrail ve Kenya'da ihracatın gelişmesinde önemli rol oynamaktadırlar [1].

Ülkemizde ise 28 ilde süs bitkileri üretimi yapılmaktadır. Ülkemizin dünya süs bitkileri ihracatındaki yeri, son sıralardadır. Ülke sıralamalarına baktığımızda; Hollanda, İtalya, Danimarka, Kolombiya, Kanada, Belçika, Almanya, Kenya, İspanya, Fransa, Ekvator, İsrail, Kosta Rica, ABD gibi ülkelerden çok daha sonra yer aldığını görmekteyiz. İhracatta Hollanda ilk sıradadır [4].

Türkiye'de Marmara ve Ege Bölgesinde yapılan üretimler genellikle iç pazara yönelik olmaktadır. Ancak Antalya bölgesinde çoğunlukla seralarda olmak üzere yüksek kaliteli ürünler ihraç edilmektedir. Dünya istatistiksel verilerine baktı̆ııızda canlı bitkiler ihracatındaki yapımızı tekrar gözden geçirmemiz ve stratejiler üretmemiz gerçeği ortaya çıkmaktadır [8].

$\mathbf{8 1} \mid \mathrm{P}$ a g e

www.iiste.org 


\section{3. Üretim Üssü Faaliyet Alanlarının Belirlenmesi}

Gerçekleştirilecek stratejik planlamalar doğrultusunda ortak üretim üssü modellemesi çalışmaları ile üretimi gerçekleştirilecek olan ürünler dış mekân süs bitkileri ağırlıklı olacaktır.

Bu üretim sürecinde belirlenmiş üretim stratejilerine göre; "faaliyet alanının” geliştirilmesi 5 bölümde toplanan çalışmaların yapılması önerilmiştir.

\section{A. Etüt / Araştırma ve Planlama Çalışmaları}

a) Kurum İçi Kapasite Araştırması

b) Kurum İçi Ürün Geliştirme Stratejisi

c) Kurum İç Kontrol Sistem Yönetimi

d) Kurum Yönetim Bilgi Sisteminin Gelişimi

e) Üretim Köyünün Kurulmasına Yönelik İşlemler

B. Proje Uygulama Çalışmaları
a) Arazi Dağıtımı
b) Arazi Kullanım Planlaması Çalışmaları
c) İnşaat Hizmetleri

C. Arazi İmar İhya, Islah ve Altyapı Çalışmaları
a) Arazi Geliştirme Hizmetleri
b) Toplulaştırma, Arazi, Sulama Hizmetleri
c) Diğer Hizmetler

D. Ë̆itim Hizmetleri
a) Teknik Hizmet İçi Eğitim
b) Yönetimsel Hizmet İçi Eğitim
- İhracat, Pazar Yönetimi, Ticari İstihbarat, Finans Yönetimi vs.

E. Danışmanlık ve Denetim Hizmetleri
a) Hukuki Danışmanlık
b) Denetim Hizmetleri
c) Mevzuat Hazırlama ve Güncelleme
d) Diğer Hizmetler alanlarında sektörel gelişim süreçlerine yönelik yapılacak çalışmalardır.

\section{Paydaş Analizi \\ 4.1. İç Paydaşlar}

Planlama sürecinde, üretim ve gelişime etki edebilecek faktörlerin üretim üssü planlamasına katılan kurum/kuruluş yetkilileri ve plan yürütücülerinin yapacağı görüşlerin belirlenmesi amacına yönelik oluşturulması planlanan paydaşlardır. Burada çalışmalarda daha objektif ve açık bir şekilde bilgilere ulaşmak için yapılan çalışmalardır. Bu çalışmada belirli soruların içerdiği anketler firmalara uygulanacaktır (Arazi kullanma, kapasite, değerlilik, finans yönetimi, yatırım gibi konular)

\subsection{Dış Paydaşlar}

Planlamanın daha verimli olabilmesi adına, paydaş beklentilerinin çalışmaya yansıtılmasını sağlamak amacıyla ilgili kurum ve kuruluşun yapısına göre farklı kademe ve görevli kişiler ile yapılacak görüşmeleri kapsar. Yapılacak paydaş görüşmeleri, analizleri kritik farklı bakış açısı kazandırılmasını sağlayabilecektir. Bu süreçte farklılaşmayı beraberinde getirecektir.

\section{Geleceğe Bakış}

26 Nisan 2005 tarihli Ortak Piyasa Düzenlerine Uyum konusunda çalışma grupları tarafindan izlenecek yola ilişkin yapılan toplantı neticesinde hazırlanan tutanak bağlamında, çalışma grupları tarafından, ilgili AB mevzuatı ile Türk mevzuatının karşılaştırılması, ürünlere ilişkin standartların ve dış ticaret düzenlemelerin uyumlaştırılması ve oluşturulması gereken idari yapılar gibi konuları içeren bir rapor hazırlamaları talep edilmiştir. Bu kapsamda, Çiçekçilik Çalışma Grubu üyeleri tarafından bir rapor hazırlanmıştır [3]. 
Ülkemizdeki kesme çiçek ve süs bitkileri mevzuatlarının AB deki mevzuatlara uyumlaştırılması için gerekli kuralların konulması gerektiği belirtilmektedir. Bu nedenle genel olarak yapılması gerekenler aşağıdaki gibi sıralanmıştır:

1. Öncelikle, ülkemizde Ulusal Tarım Politikası'nın oluşturulmasına yönelik kurallar belirlenmelidir. (Yasa, Yönetmelik ve Yönergeler düzeyinde)

2. Bu kuralların belirlenmesinden sonra, Ulusal Tarım Politikası'nın oluşturulmasına hizmet edecek olan Süs Bitkileri Piyasa Düzeni’nin oluşturulmasına yönelik kurallar konulmalıdır.

3. Bu düzenlemelerde altyapıyı oluşturacak olan standartların TSE standartları ile uyumlu olması sağlanmalıdır.

4. $\mathrm{Bu}$ düzenlemelerin getireceği yükümlülüklerin aşılmasında ve mevzuat uyumlarının sağlanmasında $\mathrm{AB}$ ile işbirliğine girilerek ilgili fonlardan destek sağlanmalıdır.

5. Ülkemiz süs bitkileri sektöründe kalite ve üretimin artırılması yanında serbest rekabet şartlarında sürekliliğin sağlanması için gerekli çalışmalar yapılmalıdır.

Ayrıca ülkesel ölçekte süs bitkileri sektörü için yapılması gerekenler de aşağıdaki gibi belirlenmiştir:

1. Sektör altyapısının diğer üye $A B$ ülkelerindeki altyapı ile uyumlu hale getirilmesi. $\mathrm{Bu}$ kapsamda işletme bazında optimum üretim alanı büyüklüğünün sağlanması, seraların kaliteli ve yüksek verime hizmet edecek standartlara getirilmesi, bilgi ve teknolojinin kullanılabilmesi için altyapının oluşturulması, ülke çevresel şartları da göz önünde tutularak ürün çeşitliliğinin sağlanması,

2. Teknik elemanların ve üreticilerin eğitilmesi

3. Ülkemiz ekolojik koşullarının belirlenmesi ile rekabet gücü yüksek olan çeşitlerin üretiminin sağlanması.

4. Sektörün gelişimini sağlayacak desteklerin verilmesi. Bunlar arasında eğitim desteğinin verilmesi, kargo desteğinin verilmesi, ihracata yönelik desteklerin arttırılması, tarımda çalışan iş gücünün desteklenmesi, tarımsal girdilerin (elektrik ve doğal gaz gibi) desteklenmesinin sağlanması ve doğrudan gelir desteği uygulaması yerine kaliteli üretimin artırılmasına yönelik desteklemelerin yapılması bulunmaktadır.

Tüm bu çalışmaların sonucunda ulaşılması beklenen hedefler ise şu şekilde sıralanmıştır:

$\checkmark$ Sektörün piyasa düzeni oluşturulması sağlanabilecek,

$\checkmark$ Uygun önlemler yolu ile rasyonel pazarlama ve istikrarlı piyasa oluşturulabilecek,

$\checkmark$ Ortak kalite standartlarının uygulanması sağlanabilecek

$\checkmark \quad$ Kalite denetimine olanak sağlanacak

$\checkmark \quad$ Fiyat istikrarının sağlanabilmesi kolaylaşacak

$\checkmark \quad$ İthalatta gümrük tarifelerinin uygulanmasına yardımcı olacak

$\checkmark$ İthalata ve ihracata ilişkin düzenlemelerin koordinasyonu sağlanacak

$\checkmark$ Sektörün önü açılacak ve serbest rekabet şartlarında kaliteli ve optimum düzeyde bir üretimin ve sürekli bir pazarın oluşmasının altyapısı oluşturulacaktır

\section{1. Dış Mekân Süs Bitkileri Sektöründe Kurumsal Kimliğin Yeniden Tanımlanması}

Diş mekân süs bitkilerinde oluşturulacak ve planlanan kümelenme projesinde sektörel olarak kurumsal yap1 yeni dizayn edilecektir, edilmelidir. İhracat ve ürün potansiyel verimlilik koordinasyonunu sağlamak için bu bir zorunluluk olarak karşımıza çıkmaktadır. Bu yapı yeni bir modelleme, ülkemizde diğer üreticilere de örnek bir model oluşturacaktır. Sektörün bugün, içinde bulunduğu şart ve işletme yönetimi stratejileri ile gelişim mümkün gözükmemektedir. Stratejik inovasyon zorunluluktur.

\subsubsection{Misyonu}

"D1ş Mekân Süs Bitkileri sektöründe yönetim, koordinasyon bütünlüğü ile üretimi dünya rekabet seviyesine getirerek ihracatı farklı ürünlerle gerçekleştirmek.”

\subsubsection{Vizyonu}

"Dış Mekân Süs Bitkileri sektöründe ekonomik değerliliği yüksek, farklılaşmış ürünler üretebilen, koordinasyon ve birlikteliğin entegrasyonunun sağlandığı bir projeyi başarmak, geliştirmek ve örnek model olmak."

83 | P a g e

www.iiste.org 


\section{Sonuç ve Öneriler}

\section{$\checkmark$ Ortak Üretim Üssü Planlaması Sonucu Ortaya Çıkacak Kritik Başarı Faktörleri}

Planlamanın destek yapısını oluşturacak kritik başarı faktörleri şu şekilde sıralanmıştır.
a) Sektörel Organizasyonda Ür Kurumsallaşma ve Yönetim
c) Finansman Yönetimi
d) Mevzuat Bilgisi
e) İnsan Kaynakları ve Eğitim
f) Bilgi Sistemi
g) Teknik ve Fiziki Altyap1, Entegrasyon
h) Pazar Bilgisi / Yönetimi
i) Lojistik Yönetimi
j) Ortaklık Kültürü ve Bilinci

Temel ilke ve değerliliğin sonucu olarak da,

- Verimlilik

"Kaynakları etkin kullanarak en yüksek faydayı sağlamak"

- Katılımeilık

"Hizmet entegrasyonunu sağlamak"

- Firma Refahını Amaçlamak

"Üretim maliyetlerini azaltmak ve gelir düzeyini yükseltmek"

- Hakkaniyet

"Tarafsız ve adil olmak, davranmak" ilkeleri öngörülmektedir.

$\checkmark \quad$ Dlş Mekân Süs Bitkileri Sektöründe Çözümlenmesi Önerilen Stratejik Konular

Planlama kapsamında stratejik amaçlara ulaşmak için öncelikle 23 adet stratejik konu belirlenmiş ve öncelik yapısı çalışması yapılmıştır.

1. Arazinin Toplulaştırılması

2. Kurumsallaşma / Yeniden Yapılanma

3. Bilgi Sistemi

4. Arazi Kullanım Planlaması

5. Toprak Etüt Ve Haritalama

6. Mevzuat / AB Süreci

7. Arazi Dağıtımı

8. Arazi İçi Geliştirme Çalışmaları

9. Mali Yapısı

10. Eğitim Planlama ve Oluşturma

11. Teknik Altyapının Sağlanması

12. Motivasyon Yönetimi

13. Stratejik Hedeflerin Yönetimi

14. Koordinasyon

15. Kurumsal Genişleme (Entegrasyon)

16. Tarımsal Verimlilik

17. Proje Yönetimi

18. İşletme Büyüklüğü Gelişim

19. Denetim ve Kontrol

20. Planlama ve Projelendirme

21. Sulama Yönetimi ve Gelişimi

22. İstihdam Süreci / İnsan Kaynakları Yönetimi

23. Lojistik Entegrasyon 
Belirlenen stratejik konulardan hareketle planlama yönetimi misyonu gerçekleştirmek için 4 adet stratejik amaç önerisi ortaya konulmuştur.

Stratejik Amaç - 1

- Toplulaştırmayı sağlayarak üretimi arttırmak ve geliri arttırmak / çeşitlendirmeyi sağlamak

Stratejik Amaç - 2

- Planlama ile üretim üssü stratejisini cazip hale getirmek, örnek model olmasını sağlayarak ülkemize katma değer sağlamak

Stratejik Amaç-3

- Toplulaştırarak yürütülen bir planlama yönetimi ile ortaklık bilinci ile hareket ile daha rekabetçi olunabileceğinin farkındalığını uyandırmak

Stratejik Amaç- 4

- Ülkemizin ekolojik ve işgücü kaynaklarının bu üretim için çok olumlu bir potansiyel olduğunu tescillemek ve bu sektörün ülkemizde gelişimini sağlamak, ihracat potansiyeline katkısını sağlamak.

\section{Teșekkür}

Bu çalışma; Mersin Ticaret ve Sanayi Odası tarafindan yürütülen "Dış Mekân Süs Bitkileri Sektöründe Dış Ticaret Kapasitesinin Artırılmasına Yönelik Üretici Kümelenmesi Projesi” isimli T.C. Ekonomi Bakanlığı, Uluslararası Rekabetçiliğin Artırılması (12URGE027) Projesi tarafından desteklenmiştir.

\section{Referanslar}

[1] Aslantaş, P., Yeler, O. (2016). Examination of Dutch Flower Auction in Sales and Marketing of Ornamental Plants Used in Landscape Design, International Conference on Natural Science and Engineering (ICNASE'16) Mart 19-20, Kilis.

[2] Bay, G., Süs Bitkileri Sektör Raporu, (2011). Orta Anadolu Süs Bitkileri ve Mamulleri İhracatçıları Birliği, Eylül, Antalya.

[3] Dış Mekân Süs Bitkileri Sektöründe Gelişim ve Yatırım Stratejisi (Development \& Investment Strategy for Outdoors Ornamental Plants Sector) Proje Raporları, (2011). Mersin Ticaret ve Sanayi Odası (MTSO), Mersin.

[4] Subaşi, O.S, Hocagil, M, Söğüt, Z. (2010). Doğu Akdeniz Bölgesi Dış Mekân Süs Bitkileri Sektörü Üretim, Pazarlama Yapısı ve Dışsatım Olanakları, IV. Süs Bitkileri Kongresi, 20 - 22 Ekim 2010, Alata Bahçe Kültürleri Araştırma Enstitüsü, s.41-47, Erdemli, Mersin.

[5] OASBMIB, Süs Bitkileri ve Mamulleri Sektörü Ticaretinin Son Dönem Değerlendirmesi Raporu, (2013). Orta Anadolu Süs Bitkileri ve Mamulleri İhracatçıları Birliği, Eylül, Antalya.

[6] Yeler, O. (2017). İtalya ve Hollanda Süs Bitkileri Sektörünün Üretim Yapısı, Pazarlama ve Organizasyon Modeli Açısından İncelenmesi. Kilis 7 Aralık Üniversitesi Fen ve Mühendislik Dergisi, 1 (1), 7-14.

[7] Yeler, O., Hocagil, M.M., Aslantaş, P., Alp, Ş., Özzambak, E.M. (2016). Avrupa'daki Süs Bitkileri Fidanlıklarının İncelenmesi Türkiye'deki Modelleri ile Karşılaştııılması, 6. Süs Bitkileri Kongresi, Antalya.

[8] Yeler, O., Yeler, S.T., Hocagil, M.M., Aydin, A. (2018). "Investigation of Common Cluster Model in Ornamental Plants Sector", International Journal of Scientific and Technological Research, vol.4, no.1, ss.34-40. 